\title{
Progress of Islet Transplantation over the Last 15 Years
}

\author{
Mohammed Almehthel, MD, CCD, ABIM, FRCPC, ${ }^{1}$ Breay W Paty, MD, FRCPC ${ }^{2}$ and David M Thompson, MD, FRCPC ${ }^{2}$ \\ 1. Clinical Assistant Professor; 2. Clinical Associate Professor, University of British Columbia, Vancouver, Canada
}

\begin{abstract}
Diabetes mellitus prevalence is increasing worldwide. Type 1 diabetes (T1DM), which is caused mainly by autoimmune destruction of beta cells, accounts for approximately 5-10 \% of all diabetes. Intensive glycemic control has been shown to reduce complications of T1DM. However, this has been difficult to achieve and is usually associated with frequent hypoglycemia. Islet transplantation (IT) has emerged as an acceptable method for the treatment of patients with T1DM who suffer for frequent severe hypoglycemia and/or glycemic lability. Although initial success was limited, improvement in IT has been observed over the last 15 years. The 5-year insulin independence rate approaches $30-50 \%$ in some experienced centers. Even without achieving insulin independence, IT has significant benefits including prevention of hypoglycemia, stabilization of glycemic control, reduction in some complications of diabetes, and improvement in quality of life. Here, we provide a brief review on IT including its history, selection of IT candidates, description, and complications of the procedure and outcomes.
\end{abstract}

\section{Keywords}

Type 1 diabetes, islet transplantation, brittle diabetes, beta cells, pancreas

Disclosure: Mohammed Almehthel, MD, CCD, ABIM, FRCPC, Breay W Paty, MD, FRCPC, and David M Thompson, MD, FRCPC, have no conflicts of interest to declare. No funding was received for the publication of this article

Open Access: This article is published under the Creative Commons Attribution Noncommercial License, which permits any noncommercial use, distribution, adaptation, and reproduction provided the original author(s) and source are given appropriate credit.

Received: September 1, 2015 Accepted: September 30, 2015 Citation: US Endocrinology 2015;11(2):70-4 DOI: http://doi.org/10.17925/USE.2015.11.02.70

Correspondence: Mohammed Almehthel, MD, CCD, ABIM, FRCPC, Clinical Assistant Professor, University of British Columbia, 4102-2775 Laurel Street, Vancouver, BC V5Z 1M9,

Canada. E: dr_almehthel@hotmail.com

Diabetes mellitus (DM) is a global epidemic. ${ }^{1}$ In 2013, there were 382 million people with $\mathrm{DM}$, and this number is expected to rise to 592 million by 2035. ${ }^{2}$ Type 1 diabetes (T1DM), which is caused mainly by an autoimmunemediated destruction of beta cells within the islet of Langerhans, accounts for $5-10 \%$ of the total cases of diabetes worldwide. ${ }^{3}$ Glycemic control is the cornerstone of diabetes care. The Diabetes Control and Complications Trial (DCCT) demonstrated that intensive glycemic control reduces the long-term complications of hyperglycemia in T1DM. ${ }^{4}$ However, diabetic complications continue to be a significant burden in persons with T1DM. ${ }^{5}$ Additionally, intensive blood glucose control often comes at the cost of increased rate of hypoglycemia., ${ }^{6,7}$ The improvement in glycemic control was associated with a two- to sixfold increase in severe hypoglycemia in the intensive treatment arm of the DCCT. ${ }^{8}$ However, it is often challenging to attain or sustain target hemoglobin $\mathrm{A}_{1 \mathrm{c}}\left(\mathrm{HbA}_{1 \mathrm{c}}\right)$ of less than $7 \%$, especially in patients who are at risk for hypoglycemia. In the Epidemiology of Diabetes Intervention and Complication (EDIC) study, the difference in mean $\mathrm{HbA}_{1 \mathrm{c}}$ between the two original DCCT treatment groups has become statistically indistinguishable (around $8 \%$ ) during the most recent years of follow-up. ${ }^{9}$ Analysis of the National Health and Nutrition Examination Survey (NHANES) data collected between 1999 and 2000 indicated that only $37.0 \%$ of adults with diagnosed DM in the US achieved a $\mathrm{HbA}_{1 \mathrm{c}}$ below $7 \%{ }^{10}$

Many innovations have been developed to improve the management of T1DM, including insulin pumps, continuous glucose monitoring systems
(CGMS), and semi-closed loop systems. However, despite these innovations, the effective care of patients with diabetes remains challenging, with a significant proportion still suffering from hypoglycemia and long-term complications of diabetes. This has led to the efforts to preserve or restore endogenous beta cell mass, which could provide better glycemic control and help prevent long-term complications of diabetes. Whole pancreas transplantation is a successful approach to treat T1DM. However, it is still associated with significant morbidity and mortality, including peri-operative infection, graft thrombosis, and pancreatitis. To overcome the need for major surgery and its associated risks, transplantation of islet cells isolated from human cadaveric pancreata has been developed as an alternative therapeutic approach. In this article, we will provide an overview of clinical islet transplantation (IT) and its advances in the last few years.

\section{History of Islet Transplantation}

Paul Langerhans first described islets of Langerhans within the pancreas in 1869. ${ }^{11}$ In 1893, Williams reported the first attempt at $\mathrm{IT}^{12}$ in which minced sheep's pancreas was transplanted into the subcutaneous tissue of a young boy with diabetic ketoacidosis. The boy died 3 days later. The discovery of insulin in 1922 greatly improved glucose control in patients with T1DM, but the inconvenience arising from multiple daily insulin injections, frequent blood sugar measurements, hypoglycemia, and the development of diabetes complications renewed the interest in beta cellreplacement therapy. 
In 1972, Ballinger and Lacy transplanted approximately 400-600 pancreatic islets to the peritoneal cavity or to the thigh muscle in inbred diabetic Lewis rats and demonstrated in vivo function. ${ }^{13}$ In the 1980s and 1990s, many groups experimented with IT, mainly in patients with T1DM, and reported various success. ${ }^{14-27}$ Insulin independence was reported ranging from 22 days to 6 years in some cases. The results of IT gradually improved, mostly due to the progress in islet isolation and purification including the development of Ricordi chamber and the introduction of the COBE 2991 cell apheresis system for continuous density gradient purification of human islets. ${ }^{28,29}$ However, optimism regarding the success of IT was waning as insulin independence rates were reported to be less than $8 \%$ after more than 450 attempts. $^{30}$

In 2000, great progress was seen when the Edmonton group reported an insulin independence rate of $100 \%$ in seven patients with T1DM after receiving $\mathrm{IT}^{31}$ Six of those patients received two islet infusions and one received three. The regimen, known as the "Edmonton Protocol," included transplantation of adequate islet cell mass (>10,000 islet equivalents [IE] per kilogram recipient weight), immediate infusion of islets following islet isolation, and the avoidance of corticosteroids. The promising results of the Edmonton group heightened the interest in IT and the Edmonton Protocol was subsequently implemented by other groups around the world. However, the need for multiple organs to achieve insulin independence and the reduction of insulin independence rate at 3-5 years' follow-up raised the concern of the utility of IT as a treatment of T1DM. ${ }^{32}$ More recently reported IT results are more encouraging and will be discussed in details in the outcome section.

\section{Indications for Islet Transplantation}

IT is associated with multiple risks, either from the procedure itself or from the long-term immunosuppression. Therefore, the benefits from the procedure must justify the associated risks.

The eligibility criteria for IT vary from one center to another. The patient must be an adult (above 18 years old) with T1DM and an undetectable C-peptide level. The main indications for IT in most centers are T1DM with unstable glucose control despite optimal medical treatment, including the use of insulin pumps and CGMS, if available, "brittle diabetes," and/ or severe recurrent hypoglycemia especially when accompanied by impaired or absent hypoglycemia awareness. For more objectivity, some centers used previously established scores for hypoglycemia unawareness, such as Clark score with number $>4$, as an indication for severe hypoglycemia unawareness. ${ }^{33}$ Other centers developed their own scores for hypoglycemia (HYPO score) and glycemic lability (Lability index). ${ }^{34}$ The former is based on frequency, severity, and degree of hypoglycemia unawareness while the latter is calculated based on the change in glucose levels over time. Patients scoring more than 90th percentile are considered candidates for IT. Control of long-term complications of diabetes is another indication for IT, which has been addressed by some centers.

Exclusion criteria for IT generally includes elevated body mass index $\mathrm{BMI}\left(>30 \mathrm{~kg} / \mathrm{m}^{2}\right)$, as the number of transplanted islets may not meet the metabolic demand; uncontrolled hypertension; severe cardiac disease; severe concurrent illness likely to limit life or require extensive systemic treatment; active infection or evidence of ongoing or recurrent viral disease; substance abuse (including tobacco); and potential inability to comply with immunosuppression or transplantation program requirements.

\section{Islet Transplantation Procedure Donor Selection}

Most islets are isolated from donors after brain death (DBD). However, the use of donors after cardiac death (DCD) has yielded successful outcomes in some centers. ${ }^{35,36}$ Successful transplantation of living-donor islets from the distal pancreas of a mother to her daughter with type 1 diabetes has been reported. ${ }^{37}$ However, living donors are usually avoided because it may predispose the donor to complications, such as pancreatic leak, fistula, and the development of diabetes. Also, because of the need for multiple islet infusions to achieve insulin independence, a single live donor transplant would be considered inadequate in most cases.

The selection of donor pancreas for islet isolation is a critical factor in the success of clinical IT. Several donor characteristics can affect not only the number, but also the quality of the islets isolated. These characteristics include age, BMI, and cold ischemia time. Older donors are more likely to yield an adequate amount of islets, but at lower insulin secretory capacity.38,39 The rate of streptozotocin-induced diabetes reversal in athymic nude mice was higher in those receiving islets from younger donors. ${ }^{39}$ Although pancreata from younger donors yield more islets with good quality, the more fibrous nature of the pancreatic substrate of young donors may make the enzymatic digestion of the organ technically more difficult. Higher BMI has been associated with higher islet isolation outcome. ${ }^{40}$ However, islets from donors with type 2 diabetes should be avoided as their function tends to be poor. ${ }^{41}$ Most IT centers now screen donors for diabetes and exclude those with $\mathrm{HbA}_{1 \mathrm{c}}$ value of $>6.5 \%$. Shorter cold ischemic time is associated with better islet function. ${ }^{40}$ Organs with cold ischemia time $>6-8$ hours have been reported to be less optimal than organs locally procured. ${ }^{42}$

\section{Islets Isolation}

Islet isolation begins with pancreas retrieval from a cadaveric donor that requires meticulous surgery and minimal handling of the delicate organ combined with rapid cooling of the lesser sac at the time of aortic crossclamp placement and arterial flushing. This is followed by two distinct steps: pancreas digestion and islet purification.

Pancreatic digestion begins with trimming excess pancreatic fat following which the pancreatic duct is canulated to allow distention of the pancreas with collagenase, which helps separate islets from exocrine and ductal tissue. Following distension, the pancreas is cut into several pieces and agitated in a Ricordi chamber. They are then purified by density-gradient centrifugation. The final product is stained with dithizone, evaluated for purity and viability before it is transported to the angiography suite for transplantation. Purified islets are counted as the number of IE, where one IE is an islet of diameter $150 \mu \mathrm{m}$. Gram-stain analysis is also performed.

\section{Islet Infusion}

Many recipient sites have been considered for IT. The vast majority of IT have been performed percutaneously into the portal vein and the islets lodge in the liver as they are too large to pass through the sinusoids. This site has been used by most IT centers because it is easily accessible, it provides a physiological release of insulin into the portal system, 
and it has been associated with high level of graft function. However, it may expose islets to a low oxygen content (compared with the native pancreas) and to toxic blood components.

\section{Procedure Complications}

In 2011, the Collaborative Islet Transplant Registry (CITR), which collects data from multiple transplant centers worldwide, reported nearly $50 \%$ of patients presented with a side effect within the first year of transplantation: half of them were potentially life-threatening and related to the infusion; the other half were usually minor and related to the immunosuppression. ${ }^{43}$

\section{Procedure-related Complications}

1. Hemorrhage or hematoma. This was not uncommon to be reported early on ( $8 \%$ in Edmonton series and $15 \%$ by CITR). ${ }^{43,44}$ Fortunately, bleeding is rare due to the development of methods to eliminate the catheter tract, including Avitene paste and coils. ${ }^{45}$

2. Portal vein thrombosis. This has been reported to be $<2 \%$ by CITR $^{43}$ and $3-5 \%$ by the Edmonton group. ${ }^{44}$ This can be reduced by including unfractionated heparin (70 units/ $\mathrm{kg}$ ) in the islet preparation and by the administration of systemic anticoagulation after the IT procedure.

3. Other rare complications reported include bile leak, puncture site pain, transient liver enzymes elevation, gallbladder perforation, and transient vitreous hemorrhage related to sudden blood glucose normalization. .33,44 $^{4}$

\section{Immunosuppression-related Complications}

These side effects include leukopenia, lymphopenia, anemia, opportunisitic infections, diarrhea, and the rare developments of neoplasms, especially skin cancers and lymphoma. Side effects mainly related to mammalian target of rapamycin (mTOR) inhibitors include mouth ulcers, edema, hypertension, dyslipidemia, and ovarian cysts. Hyperimmunization due to the appearance of anti-donor-specific human leukocyte antigen antibodies may develop, which could be a barrier to further transplants (islet, pancreas, or kidney). ${ }^{43}$ Renal failure and proteinuria has been reported by some centers especially if a combination of calineurin inhibitors and sirolimus are used for immunosuppression maintenance. ${ }^{46,47}$

\section{Islet Transplantation outcomes}

Insulin independence has been considered the ultimate goal of IT. However, other outcomes can be beneficial and should be considered when assessing islet outcome.

\section{Insulin Independence and Partial Graft Function}

Insulin independence can be defined as freedom from the need to take exogenous insulin, with adequate glycemic control, often defined by an $\mathrm{A}_{1 \mathrm{c}}$ $<6.5 \%$, fasting blood glucose (FBG) $<7.8 \mathrm{mmol} / \mathrm{l}(130 \mathrm{mg} / \mathrm{dl}$ ), and 2-hour postprandial glucose $<10.0 \mathrm{mmol} / \mathrm{l}(180 \mathrm{mg} / \mathrm{dl})$. Partial graft function can be defined as detectable C-peptide ( $>0.3 \mathrm{ng} / \mathrm{ml}$ [1 nmol/l or $99 \mathrm{pmol} / \mathrm{l}]$ ) and a requirement for insulin or inadequate glycemic control. Some centers use beta score to assess graft quality, which ranges from 0 (no graft function) to 8 (excellent graft function). ${ }^{48}$ Score $\geq 3$ is necessary to prevent hypoglycemia and score $\geq 7$ is required to optimize glycemic control and graft duration. ${ }^{49}$

In the original Edmonton study, seven out of seven patients were insulin independent at 1 year. ${ }^{31}$ However, an international multicenter trial funded by the National Institute of Health and the Immune Tolerance Network was published in 2006 and reported an insulin independence of $36 \%$ at
2 years. ${ }^{50}$ The success rate varied among different centers: some achieving $100 \%$ insulin independence while other, less experienced centers, had more limited success. A follow-up study from Edmonton group in 65 transplanted patients showed insulin independence rate of $10 \%$ at 5 years although around $80 \%$ of patients had detectable C-peptide level, which is indicative of islet graft function. ${ }^{32}$ With improvement in donor selection process, islet isolation, and purification techniques, immunosuppression agents and posttransplantation follow-up, insulin independence rate has improved with time. According to the most recent data from the CITR, the insulin independence rate at 3 years posttransplantation has increased from $27 \%$ in the early days to $44 \%$ most recently with a significant detectable C-peptide rate $(>0.3 \mathrm{ng} / \mathrm{ml}[1 \mathrm{nmol} / \mathrm{l}$ or $99 \mathrm{pmol} / \mathrm{l}])$. ${ }^{43}$ The 5 -year insulin independence rate currently varies from $25 \%$ to $50 \%$ depending on experience of the transplantation site. ${ }^{43}$ The figure of $50 \%$, which is similar to the results of whole pancreas transplantation, has led to medical insurance reimbursement of IT in some countries e.g. Canada, UK, Sweden, Switzerland, France, Italy, and Belgium. ${ }^{43}$ In Vancouver, the 5-year insulin independence rate in 2010 in 32 transplanted patients was $62 \%$ regardless of the number and time of IT infusions and $29 \%$ post last IT infusion. ${ }^{51}$ The C-peptide level was detectable in $66 \%$ of those patients at 5 years. ${ }^{52}$

\section{Stabilization of Glycemic Control and Prevention of Hypoglycemia}

IT is highly effective in stabilization of glycemic control, prevention of severe hypoglycaemia, and regaining hypoglycemia awareness. ${ }^{32,53}$ The HYPO score was significantly lower in patients who received IT compared with pretransplantation scores and scores from unselected intensively treated patients with T1DM. ${ }^{32}$ CITR data showed an absence of severe hypoglycemia in patients who received IT as long as they maintain some graft function. ${ }^{53}$

\section{Glycemic Control}

In most studies, $\mathrm{HbA}_{1 \mathrm{c}}$ must be $<6.5 \%$ in patients who achieve insulin independence. Patients with partial graft function, which is indicated by a positive C-peptide level, maintained very glycemic control compared with C-peptide-negative subjects ( $\mathrm{HbA}_{1 \mathrm{c}} 6.7 \%$ versus $9.0 \%$ ) and significantly lower insulin requirements than pretransplant $(0.34$ versus $0.66 \mathrm{u} / \mathrm{kg}$ / day). ${ }^{32}$ In the Vancouver prospective crossover cohort on IT waiting list, $\mathrm{HbA}_{1 \mathrm{c}}$ was $6.6 \pm 0.7 \% 3$ years after transplantation compared with $7.5 \pm 0.9 \%$ in patients on best medical therapy. ${ }^{54}$ CITR data showed similar results. ${ }^{53}$

\section{Long-term Complications of Diabetes}

Several studies demonstrated a favorable effect of IT on the microvascular complications of diabetes. Compared with patients on the best medical therapy, less worsening of retinopathy accompanied by improvement in retinal vascularization was reported. ${ }^{55}$ Our group in vancouver reported excellent outcomes for retinopathy, with no subject in the transplant group experiencing progression of retinopathy. ${ }^{54}$ The Edmonton data also suggest a benefit for retinopathy compared with T1DM controls. ${ }^{56}$

Studies in Vancouver and Edmonton showed stabilization or improvement of diabetic neuropathy after IT. ${ }^{32,54,57,58}$ This is consistent with the beneficial effect of whole pancreas transplantation. ${ }^{59}$

Data from Vancouver showed that the rate of decline in the glomerular filtration rate is more rapid for medically treated subjects than post IT 
(1.27 versus $2.98 \mathrm{ml} /$ minute/year; $\mathrm{p}<0.0001) .{ }^{54}$ We believe that this was achieved by avoiding sirolimus in combination with tacrolimus, which have deleterious effects on the kidneys. Certainly, this provided reassurance since earlier results showed either stabilization or decline in renal function after IT.60,61

Few studies examined the effect of IT on macrovascular complications of diabetes. Carotid intima-media thickness has been shown to improve after IT compared with pretransplantation levels, and progressed more slowly in patients who received islet after kidney transplantation compared with patients with T1DM who received only kidney transplantation. ${ }^{2}$ However, this was not replicated by a study from our center. ${ }^{63}$

\section{Quality of Life}

Unstable or brittle diabetes has been shown to be associated with lower quality of life (QOL) scores (46 \% versus $7 \%$ in stable patients). ${ }^{64}$ Long-term improvement in QoL has been reported universally after IT.65-67 This was related mainly to the resolution of hypoglycemia episodes and the fear associated with their life-threatening effects. This argues with the significant effect of IT even if insulin independence is not achieved.

\section{Current Status of Islet Transplantation and Future Perspectives}

While significant progress has been made in the IT field, many obstacles remain that preclude its widespread application. These obstacles include limited islet supply, the need for long-term immunosuppression with its consequences, loss of graft function over time, finding the most appropriate site for transplantation, and the difficulty of monitoring graft function.

\section{Islet Cell Supply}

Insulin independence has been reported after using islets isolated from a single donor. ${ }^{68,69}$ However, this is usually achieved only after multiple islet infusions from multiple donors. ${ }^{53}$ Efforts are underway to find alternative and sustained sources of viable islets e.g. porcine islets or embryonic/ adult stem cells.

\section{Long-term Immunosuppression}

As discussed above, long-term immunosuppression is associated with significant side effects. Strategies to eliminate the need for chronic immunosuppression include the use of encapsulated islets that confer immune isolation while providing adequate exchange of nutrients to islet cells, which may allow long-term survival after transplantation using short-term or lower levels of immunosuppression (systemically or locally). Modifications of immunosuppression have also been an active area of research with the aim of improving long-term islet graft function.

\section{Alternative Transplantation Sites}

Currently, the portal circulation is the most common site for islets infusion. However, islet grafts may be exposed to multiple stressors including environmental toxins, particularly medications, absorbed from the gastrointestinal tract. Additionally, transplanted islets are exposed to higher concentration of glucose and lipids from the portal circulation, which may be toxic to the newly transplanted islets. Alternative sites, more suitable for islet graft survival, have been investigated in recent years including the omentum, brachioradialis, bone marrow, and peritoneal cavity.

\section{Monitoring Islet Graft Function}

Posttransplant monitoring of intraportal islets to help guide therapy has been challenging. Reduction of C-peptide concentrations and/ or an increase in insulin dose requirements may be late signs of islet graft rejection. Random biopsy sampling is only successful in $30 \%$ of attempts and may not provide timely answers as samples are prepared and analyzed..$^{70}$ Imaging modalities may provide a more timely answer to posttransplant islet status in the future. Magnetic resonance imaging (MRI), using islets labeled with a paramagnetic compound, can provide relatively high spatial resolution, but lacks long-term application and may be limited by iron overload. ${ }^{71}$ Positron emission tomography using 18F-fluorodeoxyglucose-labeled islets may provide superior sensitivity and specificity compared with MRI and has already elucidated the early posttransplant loss of islets. ${ }^{72}$ However, longer-term monitoring of islets in the portal site has remained elusive owing to islet dispersion and washout of radiotracers. Different immunological markers to monitor for rejections are currently being investigated. ${ }^{73-76}$

\section{Other Limitations and Current Status}

In addition to above limitations, financial barriers have also hindered the widespread use of IT in the US and other countries. Until the transplantation technology is considered successful enough to be labeled therapeutic rather than experimental, the costs of IT must be covered by research funds. Some patient advocates and islet researchers are advocating that IT should be recognized as a clinical therapy. The National Institutes of Health supports studies that are working toward obtaining US Food and Drug Administration licensure to reclassify IT as therapeutic.

In Canada, some provinces reimburse IT as standard clinical care in carefully selected individuals. Similarly, IT is no longer considered experimental in countries, such as the UK, Sweden, Switzerland, France, Italy, and Belgium.

\section{Conclusion}

There has been significant progress in the IT over the last 15 years. The success and safety of the procedure have continued to improve. Insulin independence rates have also improved, approaching 30-50 \% in experienced centers. Even without achieving insulin independence, IT has significant benefits including hypoglycemia prevention, stabilization of glycemic control, reducing long-term microvascular complications of diabetes, and improving QoL. However, many challenges remain, including the need for long-term immunosuppression with its associated risks, the requirements of more than one donor organ to achieve insulin independence, and the shortage of islet supply. Until these hurdles are overcome, IT will not be an alternative to conventional insulin therapy for the vast majority of patients. Nevertheless, IT can be a life-changing to a subset of patients with frequent, severe hypoglycemia and/or glycemic lability.
1. Shaw JE, Sicree RA, Zimmet PZ, Global estimates of the prevalence of diabetes for 2010 and 2030, Diabetes Res Clin Pract, 2010;87:4-14.

2. Guariguata L, Whiting DR, Hambleton I, et al., Global estimates of diabetes prevalence for 2013 and projections for 2035 for the IDF Diabetes Atlas, Diabetes Res Clin Pract, 2014;103:137-49.
3. Diagnosis and classification of diabetes mellitus, Diab Care, 2009;32(Suppl. 1):S62-S67.

4. Diabetes Control and Complications Trial Research Group, Effect of intensive diabetes treatment on the development and progression of long-term complications in adolescents with insulin-dependent diabetes mellitus: Diabetes Control and
Complications Trial, J Pediatr, 1994;125:177-88.

5. Libby P, Nathan DM, Abraham K, et al., Report of the National Heart, Lung, and Blood Institute-National Institute of Diabetes and Digestive and Kidney Diseases Working Group on Cardiovascular Complications of Type 1 Diabetes Mellitus, Circulation, 2005;111:3489-93. 
6. The Diabetes Control and Complications Trial Research Group, The effect of intensive treatment of diabetes on the development and progression of long-term complications in insulin-dependent diabetes mellitus, N Eng/ I Med, 1993:329:977-86.

7. Nathan DM, Cleary PA, Backlund JY, et al., Intensive diabetes treatment and cardiovascular disease in patients with type diabetes, N Eng/ J Med, 2005;353:2643-53.

8. The DCCT Research Group, Epidemiology of severe hypoglycemia in the diabetes control and complications trial, Am J Med, 1991;90:450-9.

9. The DCCT/EDIC Research Group, Epidemiology of Diabetes Interventions and Complications (EDIC). Design, implementation, and preliminary results of a long-term followup of the Diabetes Control and Complications Trial cohort, Diabetes Care, 1999;22:99-111

10. Saydah SH, Fradkin J, Cowie CC, Poor control of risk factors for vascular disease among adults with previously diagnosed diabetes, JAMA, 2004:291:335-42.

11. De Panfilis G, Paul Langerhans sesquicentennial, J Invest Dermatol, 1997:109:120-1.

12. Williams $P$, Notes on diabetes treated with extract and by grafts of sheep's pancreas, BMJ, 1894;12:1303-4.

13. Ballinger WF, Lacy PE, Transplantation of intact pancreatic islets in rats, Surgery, 1972;72:175-86.

14. Largiader F, Kolb E, Binswanger U, A long- term functioning human pancreatic islet allotransplant, Transplantation, 1980;29:76-7.

15. Scharp DW, Lacy PE, Santiago JV, et al., Insulin independence after islet transplantation into type I diabetic patient, Diabetes, 1990;39:515-8

16. Tzakis AG, Ricordi C, Alejandro R, et al., Pancreatic islet transplantation after upper abdominal exenteration and liver replacement, Lancet, 1990;336:402-5.

17. Warnock GL, Kneteman NM, Ryan E, et al., Normoglycaemia after transplantation of freshly isolated and cryopreserved pancreatic islets in type 1 (insulin- dependent) diabetes mellitus, Diabetologia, 1991:34:55-8.

18. Scharp DW, Lacy PE, Santiago JV, et al., Results of our first nine intraportal islet allografts in type 1, insulin-dependent diabetic patients, Transplantation, 1991;51:76-85.

19. Warnock GL, Kneteman NM, Ryan EA, et al., Long-term followup after transplantation of insulin-producing pancreatic islets into patients with type 1 (insulin-dependent) diabetes mellitus, Diabetologia 1992:35:89-95.

20. Gores PF, Najarian JS, Stephanian E, et al., Insulin independence in type I diabetes after transplantation of unpurified islets from single donor with 15-deoxyspergualin, Lancet, 1993;341:19-21.

21. Soon-Shiong $\mathrm{P}$, Heintz RE, Merideth $\mathrm{N}$, et al., Insulin independence in a type 1 diabetic patient after encapsulated islet transplantation, Lancet, 1994;343:950-1.

22. Carroll PB, Rilo HL, Alejandro R, et al., Long- term (>3-year) insulin independence in a patient with pancreatic islet cel transplantation following upper abdominal exenteration and liver replacement for fibrolamellar hepatocellular carcinoma, Transplantation, 1995;59:875-9.

23. Luzi L, Hering BJ, Socci C, et al., Metabolic effects of successfu intraportal islet transplantation in insulin-dependent diabetes mellitus, J Clin Invest, 1996;97:2611-8.

24. Alejandro $\mathrm{R}$, Lehmann $\mathrm{R}$, Ricordi $\mathrm{C}$, et al., Long-term function (6 years) of islet allografts in type 1 diabetes, Diabetes, 1997:46:1983-9.

25. Secchi A, Socci C, Maffi P, et al., Islet transplantation in IDDM patients, Diabetologia, 1997;40:225-31

26. Keymeulen B, Ling Z, Gorus FK, et al., Implantation of standardized beta-cell grafts in a liver segment of IDDM patients: graft and recipients characteristics in two cases of insulin-independence under maintenance immunosuppression for prior kidney graft, Diabetologia, 1998;41:452-9.

27. Oberholzer J, Triponez F, Mage R, et al, Human is transplantation: lessons from 13 autologous and 13 allogeneic transplantations, Transplantation, 2000;69:1115-23.

28. Ricordi C, Lacy PE, Scharp DW, Automated islet isolation from human pancreas, Diabetes, 1989;38(Suppl. 1):140-2.

29. Lake SP, Bassett PD, Larkins A, et al., Large-scale purification of human islets utilizing discontinuous albumin gradient on IBM 2991 cell separator, Diabetes, 1989:38(Suppl. 1):143-5.
30. Brendel MD, Hering BJ, Schultz AO, Bretzel RG, International Islet Transplant Registry, Newsletter 9, 2001:8.

31. Shapiro AM, Lakey JR, Ryan EA, et al., Islet transplantation in seven patients with type 1 diabetes mellitus using a glucocorticoid-free immunosuppressive regimen, N Eng/ I Med 2000;343:230-8

32. Ryan EA, Paty BW, Senior PA, et al., Five-year follow-up after clinical islet transplantation, Diabetes, 2005;54:2060-9.

33. Clarke WL, Cox DJ, Gonder-Frederick LA, et al., Reduced awareness of hypoglycemia in adults with IDDM: a prospective study of hypoglycemic frequency and associated symptoms, Diabetes Care, 1995:18:517-22

34. Ryan EA, Shandro T, Green K, et al., Assessment of the severity of hypoglycemia and glycemic lability in type 1 diabetic subjects undergoing islet transplantation, Diabetes, 2004;53:955-62

35. Markmann JF, Deng S, Desai NM, et al., The use of non-heatbeating donors for the isolated pancreatic islet transplantation, Transplantation, 2003;75:1423-9.

36. Saidi RF, Bradley J, Greer D, et al., Changing pattern of organ donation at a single center: Are potential brain dead donors being lost to donation after cardiac death? Am J Transplant 2010;10:2536-40.

37. Matsumoto $S$, OKitsu T, Iwanaga $Y$, et al., Insulin independence after living-donor distal pancreatectomy and islet allotransplantation, Lancet, 2005;365:1642-4

38. Lakey JR, Warnock GL, Rajotte RV, et al., Variables in organ donors that affect the recovery of human islets of Langerhans, Transplantation, 1996:61:1047-53.

39. Ihm SH, Matsumoto I, Sawada T, et al., Effect of donor age on function of isolated human islets, Diabetes, 2006;55:1361-8.

4. Hilling DE, Bouwman E, Terpstra OT, Marang-van de Mheen P Effects of donor-, pancreas-, and isolation-related variables on human islet isolation outcome: A systematic review, Cell Transplant, 2014;23:921-8.

41. Deng $S$, Vatamaniuk $M$, Huang $X$, et al., Structural and functiona abnormalities in the islet isolated from type 2 diabetic subjects, Diabetes, 2004:53:624-32.

42. Lakey JR, Rajotte RV, Warnock GL, Kneteman NM, Human pancreas preservation prior to islet isolation. Cold ischemic tolerance, Transplantation, 1995; 59:689-94.

43. Barton FB, Rickels MR, Alejandro R, et al., Improvement in outcomes of clinical islet transplantation: 1999-2010, Diabetes Care, 2012:35:1436-45.

44. Owen RJ, Ryan EA, O'Kelly K, et al., Percutaneous transhepatic pancreatic islet cell transplantation in type 1 diabetes mellitus: radiologic aspects, Radiology, 2003:229:165-70.

45. Villinger $P$, Ryan EA, Owen $R$, et al., Prevention of bleeding after islet transplantation: Lessons learned from a multivariate analysis of 132 cases at a single institution, Am J Transplant, 2005;5:2992-8.

46. Kaplan B, Schold J, Srinivas T, et al., Effect of sirolimus withdrawal in patients with deteriorating renal function, Am J Transplant, 2004:4:1709-12.

47. Senior PA, Paty BW, Cockfield SM, et al., Proteinuria developing after clinical islet transplantation resolves with sirolimus withdrawal and increased tacrolimus dosing, Am I Transplant 2005;5:2318-23.

48. Ryan EA, Paty BW, Senior PA, et al., Beta-score: an assessment of $\beta$-cell function after islet transplantation, Diabetes Care, 2005:28:343-7.

49. Vantyghem MC, Raverdy V Balavoine AS, et al., Continuous glucose monitoring after islet transplantation in type 1 diabetes: an excellent graft function (beta-score greater than 7) is required to abrogate hyperglycemia, whereas a minimal function is necessary to suppress severe hypoglycemia (beta-score greater than 3), J Clin Endocrinol Metab, 2012;97:E2078-E2083.

50. Shapiro AM, Ricordi C, Hering BJ, et al., International trial of the Edmonton protocol for islet transplantation, N Eng/ J Med, 2006;355:1318-30.

51. Kondi J, Almehthel M, Paty BW, Thompson D, et al., The effect of Islet Cell Transplant (ICT) on Insulin Requirements in patients with type 1 diabetes. Presented at American Diabetes Association 70th Scientific Sessions, Orlando, Florida, June 27, 2010.

52. Almehthel M, Paty BW, Thompson D, et al., Variables affecting C-peptide levels after islet-cell transplantation. Presented at American Diabetes Association 70th Scientific Sessions, Orlando, Florida, June 26, 2010.
53. CITR Annual Report, 2013. Available at: http://www.citregistry. com (accessed August 16, 2015)

54. Thompson DM, Meloche M, Ao Z, et al., Reduced progression of diabetic microvascular complications with islet cell transplantation compared with intensive medical therapy, Transplantation, 2011;91:373-8

55. Venturini M, Fiorina P, Maffi P, et al., Early increase of retina arterial and venous blood flow velocities at color Doppler imaging in brittle type 1 diabetes after islet transplant alone, Transplantation, 2006:81:1274-7.

56. Koh A, Rudnisky C, Tennant $\mathrm{M}$, et al., Positive effects of clinica islet transplantation on diabetic retinopathy over 5 years, Diabetes, 2011;60(Suppl. 1):A205.

57. Albaker W, Koh A, Ryan E, et al., Diabetic peripheral neuropathy is stabilized after clinical islet transplantation 7 year follow-up study, I Clin Endocrinol Metab, 2008;93:OR26-2.

58. Fensom B, Almehthel $\mathrm{M}, \mathrm{Ao} \mathrm{Z}$, et al., Islet cell transplantation improves diabetic neuropathy compared with intensive medica therapy. Presented at American Diabetes Association 74th Scientific Sessions, San Francisco, California, June 14, 2010

59. Kennedy W, Navarro X, Goetz F, et al., Effects of pancreatic transplantation on diabetic neuropathy, N Engl I Med, 1990;322:1031-7.

60. Fung MA, Warnock GL, Ao Z, et al., The effect of medical therapy and islet cell transplantation on diabetic nephropathy: an interim report, Transplantation, 2007:84:17-22.

61. Senior PA, Zeman M, Paty BW, et al., Changes in renal function after clinical islet transplantation: four-year observational study, Am J Transplant, 2007:7:91-8.

62. Danielson KK, Hatipoglu B, Kinzer K, et al., Reduction in carotid intima-media thickness after pancreatic islet transplantation in patients with type 1 diabetes, Diabetes Care, 2013;36:450-6.

63. Fensom B, Hitchcock C, Almehthel M, et al., Islet transplantation does not change the rate of increase of carotid intimal-medial thickness compared with intensive medical therapy, Presented at American Diabetes Association 74th Scientific Sessions, San Francisco, California, June 15, 2010.

64. Tattersall RB, Brittle diabetes revisited: the third Arnold Bloom memorial lecture, Diabet Med, 1997;14:99-110.

65. Tharavanij T, Betancourt A, Messinger S, et al., Improved long term health-related quality of life after islet transplantation, Transplantation, 2008;86:1161-7.

66. Cure P, Pileggi A, Froud T, et al., Improved metabolic control and quality of life in seven patients with type 1 diabetes following islet after kidney transplantation, Transplantation, 2008:85:801-12.

67. Poggioli R, Faradji RN, Ponte G, et al., Quality of life after islet transplantation, Am J Transplant, 2006;6:371-8.

68. Hering BJ, Kandaswamy R, Ansite JD, et al., Single-donor, marginal-dose islet transplantation in patients with type 1 diabetes, JAMA, 2005:293:830-5.

69. Al-Adra DP, Gill RS, Imes S, et al., Single-donor islet transplantation and long-term insulin independence in select patients with type 1 diabetes mellitus, Transplantation, 2014;98:1007-12.

70. Toso C, Isse K, Demetris AJ, et al., Histologic graft assessment after clinical islet transplantation, Transplantation, 2009;88:1286-93

71. Toso C, Vallee JP, Morel $\mathrm{P}$, et al., Clinical magnetic resonance imaging of pancreatic islet grafts after iron nanoparticle labeling, Am J Transplant, 2008:8:701-6.

72. Eich T, Eriksson 0 , Sundin A et al. Positron emission tomography: A real-time tool to quantify early islet engraftment in a preclinical large animal model, Transplantation, 2007:84:893-8.

73. Huurman VA, Hilbrands R, Pinkse GG, et al, Cellular islet autoimmunity associates with clinical outcome of islet cell transplantation, PLOS ONE, 2008;3:e2435.

74. Huurman VA, Velthuis JH, Hilbrands R, et al., Allograft-specific cytokine profiles associate with clinical outcome after islet cell transplantation, Am J Transplant, 2009:9:382-8.

75. Han D, XU X, Pastori RL, et al., Elevation of cytotoxic lymphocyte gene expression is predictive of islet allograft rejection in nonhuman primates, Diabetes, 2002;51:562-6.

76. Han D, Xu X, Baidal D, et al., Assessment of cytotoxic ymphocyte gene expression in the peripheral blood of human islet allograft recipients: Elevation precedes clinical evidence of rejection, Diabetes, 2004;53:2281-90. 